\title{
Síndrome de Boerhaave con doble perforación esofágica. A propósito de un caso
}

\author{
Boerhaave syndrome with double esophageal perforation. About a case
}

\author{
Arturo Martínez-García*, Kymani Pérez-García, Javier Pérez-Palenzuela, Gimel Sosa-Esquively \\ José M. Díaz-Calderín \\ Servicio de Cirugía General, Hospital Clínico Quirúrgico Hermanos Ameijeiras, Universidad de Ciencias Médicas de La Habana, La Habana, Cuba
}

\begin{abstract}
Resumen
Introducción: El síndrome de Boerhaave consiste en una perforación espontánea del esófago, con alta mortalidad. Objetivo: Describir un caso de síndrome de Boerhaave con doble perforación esofágica. Caso clínico: Mujer de 33 años que acude al hospital por un cuadro emético, seguido de dolor torácico retroesternal; se realiza drenaje torácico. Se diagnostica tardíamente perforación esofágica y se traslada a una institución de nivel terciario. Se realizaron sucesivos tratamientos: videotoracoscopia y decorticación pleural, yeyunostomía alimentaria, colocación de endoprótesis esofágica, diagnóstico de nueva perforación, exclusión pilórica, colocación de nueva endoprótesis y exclusión esofágica. Conclusiones: El retardo en el diagnóstico contribuyó al desenlace fatal de la paciente.
\end{abstract}

Palabras clave: Síndrome de Boerhaave. Perforación espontanea de esófago. Empiema pleural.

\section{ABSTRACT}

Introduction: Boerhaave syndrome consists of a spontaneous perforation of the esophagus, with high mortality. Objective: To describe a case with Boerhaave syndrome with double esophageal perforation. Case report: 33-year-old female who came to the hospital for emetic symptoms, followed by retrosternal chest pain; chest drainage is performed. Esophageal perforation was diagnosed late and he was transferred to a tertiary level institution. Successive treatments were performed: videothoracoscopy and pleural decortication; alimentary jejunostomy; esophageal stent placement, diagnosis of new perforation, pyloric exclusion, new stent placement, and esophageal exclusion. Conclusions: The delay in diagnosis contributed to the fatal outcome of the patient.

Key words: Boerhaave syndrome. Spontaneous perforation of the esophagus. Pleural empyema. 


\section{Introducción}

El síndrome de Boerhaave es una condición de rara presentación que consiste en la rotura longitudinal espontánea transmural de un esófago de anatomía normal. Aunque su incidencia real en todo el mundo no está clara, algunos estudios la estiman en aproximadamente 3.1 casos por 1,000,000 personas y año1. La presencia de doble perforación esofágica constituye una forma de presentación inusual de la enfermedad, y de ahí la importancia de publicar el presente caso.

El objetivo es describir el caso de una paciente con síndrome de Boerhaave con doble perforación esofágica.

\section{Caso clínico}

Mujer de 33 años con antecedentes patológicos personales de disfagia eventual a los sólidos, que nunca fue estudiada. Ingresó al servicio de urgencias de otra institución por un cuadro clínico caracterizado por dolor torácico intenso de localización retroesternal de intensidad creciente, con irradiación a ambas bases de los hemitórax, mantenido, que no se aliviaba con los cambios posturales, antecedido de un cuadro emético intenso.

En la exploración física se documentó aspecto de enferma aguda, con mucosas ligeramente secas y normocoloreadas, con índice de masa corporal de $22 \mathrm{~kg} / \mathrm{cm}^{2}$ y temperatura de $37^{\circ} \mathrm{C}$. El murmullo vesicular estaba disminuido en los dos tercios inferiores del hemitórax izquierdo, con matidez a ese nivel sin estertores. $\mathrm{La} \mathrm{SO}_{2}$ era del $90 \%$. Taquicardia ligera: 115 latidos por minuto. Presión arterial: $110 / 70 \mathrm{mmHg}$. Exploración abdominal normal.

El hemograma mostró leucocitosis ligera con neutrofilia. La radiografía de tórax reveló radioopacidad en masa en los dos tercios inferiores del hemitórax izquierdo, con desplazamiento ligero de las estructuras de la línea media y ensanchamiento de los espacios intercostales. No se constataron signos de neumomediastino.

Se decide realizar pleurostomía mínima baja de urgencia, obteniéndose aproximadamente $1200 \mathrm{ml}$ de derrame pleural de coloración oscura, sin describir otros datos del mismo.

Se instauró antibioticoterapia de amplio espectro. Evolutivamente, por la persistencia de la fiebre, la leucocitosis y las características del líquido pleural, se sospecha una perforación esofágica y se decide realizar un esofagograma por radiografías seriadas, que evidencia una perforación del tercio inferior del esófago torácico, por lo que se decide interconsultar con los especialistas del Hospital Clínico Quirúrgico Hermanos Ameijeiras y se traslada a la paciente a la unidad de cuidados intensivos.

La paciente llega al hospital con 10 días de evolución, ventilando espontáneamente, con $\mathrm{SO}_{2}$ del $94 \%$, con sonda de Levine y Foley, leucocitosis moderada de $18,5 \times 10^{9} /$ con marcada neutrofilia (85\%) y reactantes de fase aguda elevados considerablemente, y presentando un pico febril vespertino de $39^{\circ} \mathrm{C}$.

Se le realiza una tomografía computarizada de tórax con contraste oral que corrobora la presencia de perforación a nivel del tercio inferior del esófago, con comunicación directa con la cavidad torácica izquierda, sin extravasación hacia el mediastino.

El esofagograma por fluoroscopia informa trayecto que comunica con la cavidad pleural a aproximadamente $2.7 \mathrm{~cm}$ por encima de la unión esofagogástrica, que mide $2 \mathrm{~cm}$ de longitud, en relación con fístula esofagopleural (Fig. 1).

Se instaura tratamiento antibiótico intravenoso con meropenem a razón de $1 \mathrm{~g} / 8 \mathrm{~h}$, metronidazol 0,5 g/8 h y ceftriaxona $2 \mathrm{~g} / 12 \mathrm{~h}$.

Veinticuatro horas después del traslado se decide realizar una videotoracoscopia con decorticación pleural y recolocación de sonda pleural baja más colocación de sonda pleural alta. Además, se realiza yeyunostomía alimentaria por sonda y se coordina con el Centro Nacional de Cirugía Endoscópica para la colocación de endoprótesis esofágica.

Seis días después es llevada a dicha institución, donde se corrobora la perforación de $5 \mathrm{~mm}$ a $38 \mathrm{~cm}$ de la arcada dentaria (Fig. 2) y se colocan un clip de Ovesco y una endoprótesis esofágica con cubierta siliconada y mecanismos antimigración.

El débito por la sonda pleural disminuyó significativamente y sin bilis, pero en la noche la paciente presentó dos vómitos de gran cuantía y comenzó de nuevo un débito de contenido gástrico mezclado con bilis por la sonda pleural inferior.

Se realiza esofagograma por fluoroscopia evolutivo y se diagnostica nueva perforación esofágica en el tercio medio del esófago (Fig. 3), con neumotórax de un $50 \%$ de colapso pulmonar.

Ya en estos momentos la paciente volvía a presentar fiebre de $39-39,5^{\circ} \mathrm{C}$, leucocitosis de $17 \times 10^{\circ} / /$ y como complicación sobreañadida una bronconeumonía. 


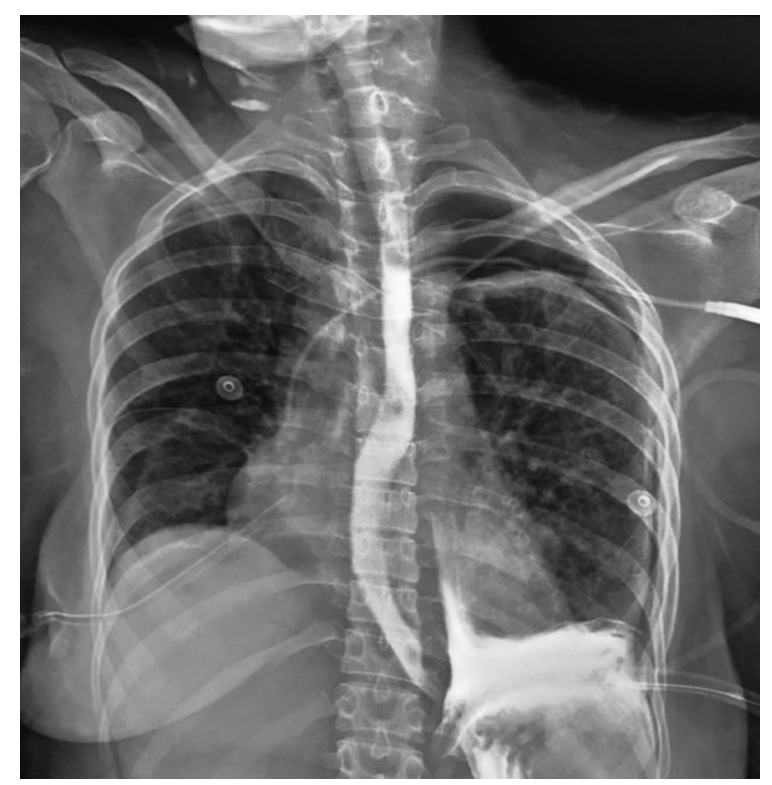

Figura 1. Esofagograma por fluoroscopia en el que se visualiza la salida de contraste desde el tercio inferior del esófago hacia la cavidad torácica.

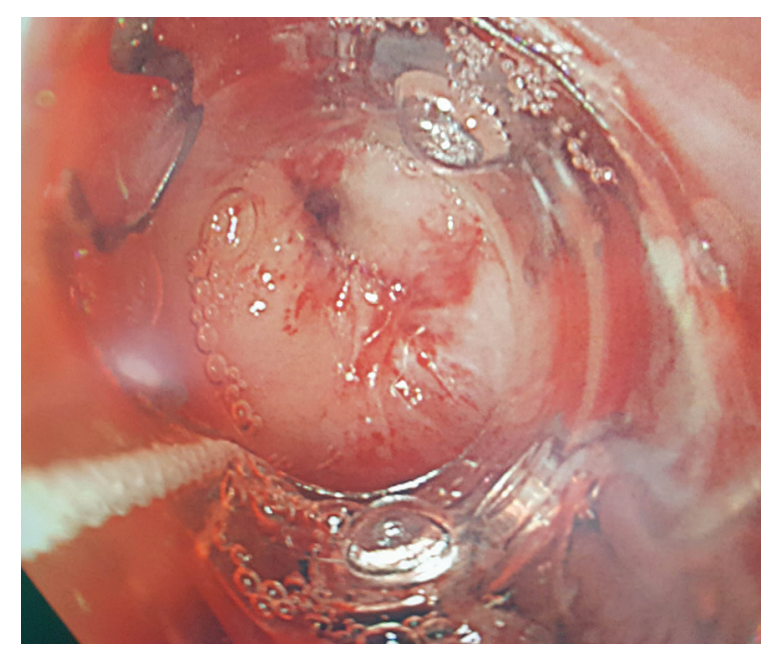

Figura 2. Endoscopia digestiva alta en la que se visualiza la perforación esofágica momentos antes de colocar un clip de Ovesco.

Se decide llevar a la paciente al quirófano de urgencias y se realiza una exclusión pilórica más colocación de sonda de gastrostomía. Se coordina nuevamente con el centro para colocación de una nueva endoprótesis a nivel del tercio medio esofágico. En el Centro Nacional de Cirugía Endoscópica, durante la endoscopia digestiva se encuentra una zona puntiforme eritematosa, deprimida, a los $26 \mathrm{~cm}$ de la arcada dentaria, pero sin extravasación de contraste a dicho nivel. No obstante, se decide colocar una nueva endoprótesis.

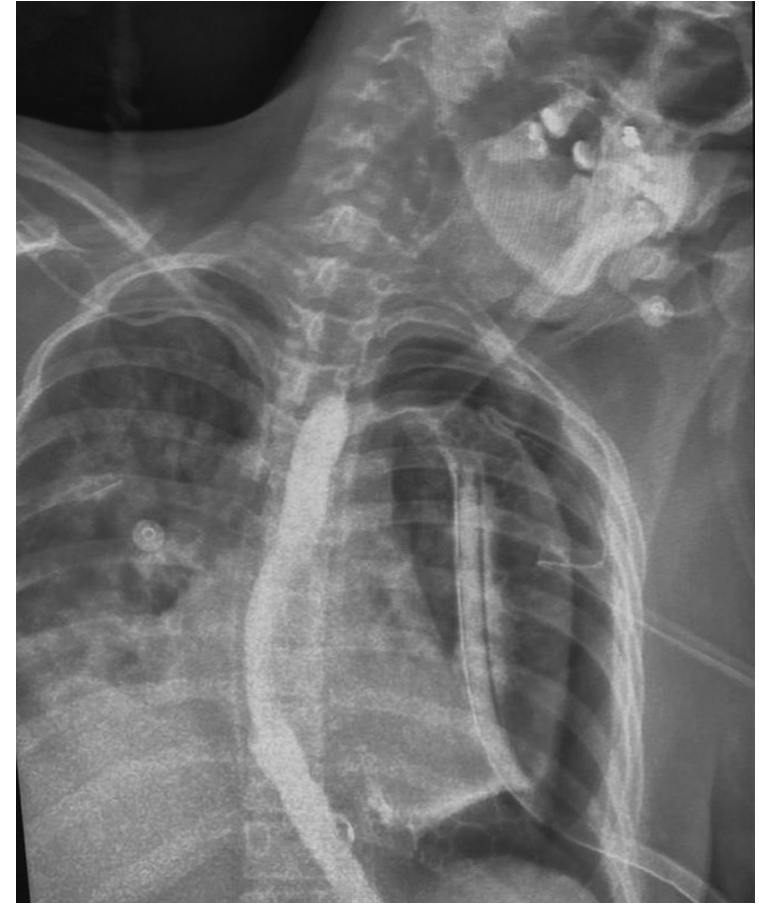

Figura 3. Esofagograma por fluoroscopia que muestra salida de contraste desde el tercio medio del esófago hacia la cavidad torácica.

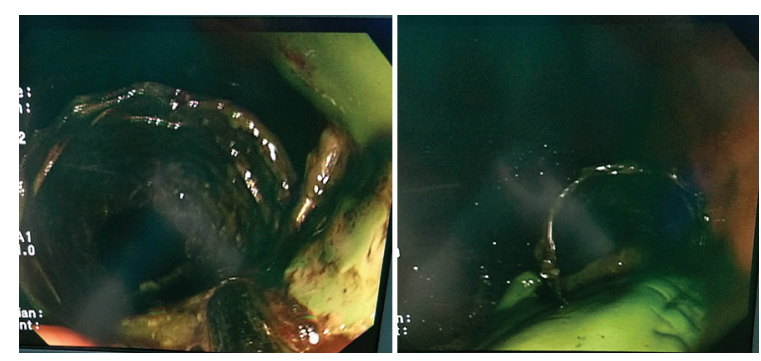

Figura 4. Imágenes de endoscopia digestiva alta en las que se observa la prótesis metálica con el recubrimiento siliconado (color verde) dislocado fuera de ella.

Presentó una mejoría ostensible, pero corta, ya que a los 3 días comenzó con picos febriles de 3 horas de evolución, vespertinos, que fueron incrementando evolutivamente, con temperaturas entre 38,5 y $39^{\circ} \mathrm{C}$. No se constató leucocitosis y por la sonda pleural inferior presentó nuevamente débito de contenido gástrico mezclado con bilis. Fue necesario colocar un tubo endotraqueal y ventilación mecánica por presencia de distrés respiratorio.

Se decide en colectivo realizar una exclusión esofágica con suturador mecánico, a nivel del esófago abdominal, previa retirada de las prótesis esofágicas. Durante la endoscopia se diagnostica migración de la prótesis inferior hacia la vertiente gástrica y pérdida 
total de la cubierta siliconada, la cual se encontraba en el estómago (Fig. 4).

Se retiran ambas endoprótesis sin accidente quirúrgico y también parte del recubrimiento siliconado. Se realiza laparotomía con gastrotomía alta y extracción del resto del recubrimiento siliconado, retirada de los puntos de la exclusión pilórica, recolocación de sonda de gastrostomía y cierre de la gastrotomía.

Evolutivamente la paciente se mantuvo ventilada, con salida escasa de contenido pleural claro por la sonda y mejoría clínica discreta. A las 30 horas del posoperatorio presentó una arritmia ventricular de difícil control, cayó en paro cardiorrespiratorio y falleció a pesar de las sucesivas maniobras de resucitación.

\section{Discusión}

El síndrome de Boerhaave es una condición de rara presentación que consiste en la rotura espontánea longitudinal transmural de un esófago de anatomía normal ${ }^{2,3}$. Esta enfermedad fue descrita por primera vez en 1724 por el médico alemán Hermann Boerhaave, profesor de medicina en la Universidad de Leiden ${ }^{4}$. Este médico realizó una publicación titulada Historia de una enfermedad grave no descrita anteriormente y habló sobre el caso del barón Jan Van Wassenaer, un almirante holandés que comenzó a vomitar y presentó dolor torácico del lado izquierdo poco después de un banquete y solo sobrevivió 24 horas tras el incidente ${ }^{5}$.

Aunque se cree que el vómito es la causa más común, otras causas incluyen levantamiento de pesas, defecación, convulsiones epilépticas, trauma abdominal, lesión por aire comprimido y parto². La mayoría de los casos ocurren en pacientes con un esófago subyacente normal, aunque la presencia de esofagitis, hernia hiatal, enfermedad de reflujo gastroesofágico asintomático, alcoholismo y úlceras también puede predisponer a esta patología ${ }^{6,7}$.

Aunque la incidencia real de la perforación esofágica en todo el mundo no está clara, algunos estudios la estiman en aproximadamente 3.1 casos por $1,000,000$ de personas y año'.

Esta perforación esofágica presenta una tasa de mortalidad de aproximadamente el $20 \%$ al $50 \%$, inclusive con tratamiento oportuno. El tratamiento quirúrgico temprano (menos de 24 horas) tiene una tasa de sobrevida aproximada del $75 \%$, pero si se aborda de forma tardía (posterior a las 24 horas) es del 35\% a $50 \%$, y del $0 \%$ si se trata posterior a las 48 horas $^{3}$.
La rotura esofágica espontánea está causada por un aumento súbito de la presión intraesofágica, que conduce a un desgarro longitudinal transmural completo en la pared del esófago ${ }^{3,5,6}$. Ocurre comúnmente en la pared posterolateral izquierda del tercio distal del esófago torácico ( $80 \%$ de los casos) debido a una debilidad anatómica, de 3 a $6 \mathrm{~cm}$ por encima del diafragma; el daño mide de 2 a $10 \mathrm{~cm}$ en la mayoría de los casos y se extiende hacia la cavidad pleural izquierda, conduciendo a inflamación mediastínica, enfisema o necrosis debido a que los contenidos gástricos ingresan al área ${ }^{3,4}$.

Estos pacientes presentan rápido deterioro por la infección extensa del mediastino, la cavidad pleural, la cavidad abdominal o el saco pericárdico con sustancias del tracto gastrointestinal ${ }^{6,7}$.

Las manifestaciones clínicas del síndrome de Boerhaave dependen de la localización de la rotura, del grado de fuga y del tiempo transcurrido desde la perforación ${ }^{6}$.

El médico debe sospecharlo en un paciente que se presente con dolor torácico retroesternal con o sin enfisema subcutáneo, sobre todo cuando se asocia con vómitos graves o de repetición ${ }^{5}$. Entre un 30\% y un $50 \%$ de los casos se presentan con vómitos, dolor torácico inferior y enfisema subcutáneo, lo que se conoce como la tríada de Mackler ${ }^{2,4-7}$.

El tratamiento inicial es fundamental y consiste en la reposición de volumen, la cobertura antibiótica de amplio espectro y la evaluación quirúrgica. El manejo del síndrome de Boerhaave puede ser conservador en los pacientes con perforación contenida sin datos de sepsis, con una sobrevida del $75 \%$.

La intervención quirúrgica con reparación esofágica primaria mediante toracotomía abierta durante las primeras 24 horas de presentación es el tratamiento de referencia para el síndrome de Boerhaave. En los últimos años se ha estudiado la efectividad de tratamientos mínimamente invasivos, tales como la toracoscopia o la laparoscopia como alternativa en pacientes hemodinámicamente estables, con presentaciones tempranas y ausencia de complicaciones sépticas ${ }^{3,7}$.

En nuestra paciente, la segunda perforación esofágica fue objeto de duda, ya que podría ser consecuencia del proceder endoscópico realizado previamente. Debido a ello, se revisaron exhaustivamente todas las imágenes de control realizadas después de la colocación de la endoprótesis, y no se constató extravasación de contraste ni imágenes de neumomediastino o de neumotórax en la fluoroscopia de control. 
Esta paciente en particular constituyó un reto en su manejo por varios factores de mal pronóstico: inicialmente, los días de evolución desde la perforación, con una escala de gravedad de Pittsburgh de 9 puntos; y a esto se añade la ocurrencia de una segunda perforación esofágica, con colocación de nueva endoprótesis y finalmente el fallo de la endoprótesis inicial con su deslizamiento hacia el estómago y pérdida del recubrimiento siliconado. Todos estos factores llevaron al deceso de la paciente a pesar de todos los intentos terapéuticos por salvarla.

\section{Conclusiones}

El manejo idóneo del síndrome se ha visto obstaculizado por su baja incidencia y el retardo en el diagnóstico, y conductas oportunas durante los primeros 10 días de enfermedad, lo que contribuyó al desenlace fatal de la paciente.

\section{Consideraciones éticas}

Esta presentación de caso se realizó conforme a los principios de la ética médica, las normas éticas institucionales y nacionales vigentes, y los principios de la Declaración de Helsinki.

\section{Responsabilidades éticas}

Protección de personas y animales. Los autores declaran que para esta investigación no se han realizado experimentos en seres humanos ni en animales.
Confidencialidad de los datos. Los autores declaran que han seguido los protocolos de su centro de trabajo sobre la publicación de datos de pacientes.

Derecho a la privacidad y consentimiento informado. Los autores han obtenido el consentimiento informado de los pacientes y/o sujetos referidos en el artículo. Este documento obra en poder del autor de correspondencia.

\section{Financiamiento}

Los autores no declaran financiamiento.

\section{Conflictos de intereses}

Los autores declaran no tener ningún conflicto de intereses.

\section{Bibliografía}

1. Rokicki M, Rokicki W, Rydel M. Boerhaave's syndrome - over 290 yrs of surgical experiences. Epidemiology, pathophysiology, diagnosis. Pol Przegl Chir. 2016;88:359-64.

2. Anwar J, Maqsood R, Soomro S. Multimodality imaging approach for the early diagnosis Boerhaave syndrome. J Ayub Med Coll Abbottabad. 2017;29:157-8.

3. Tellechea J, González J, Miranda-García P, Culetto A, D'Journo X, Thomas $P$, et al. Role of endoscopy in the management of Boerhaave syndrome. Clin Endosc. 2018;51:186-91.

4. Dinic B, llic G, Rajkovic S, Stoimenov T. Boerhaave syndrome - case report. Sao Paulo Med J. 2016;135:71-5.

5. Neira Borja J, Coronel Ruilova J, Abarca Rendón F, Pilco Asqui E. Síndrome de Boerhaave. Informe de un caso. Medicina. 2019;20:38-41.

6. Pérez Villaverde N, Soto García M, Alemán Villanueva S, Barrios Barbero A, Rodríguez Jiménez S. Síndrome de Boerhaave. Rev Clin Med Fam. 2015;8:158-61.

7. Cristóbal L, Trébol J, Recarte M, González C, Rodríguez J, Castell J, et al. Perforación esofágica espontánea o síndrome de Boerhaave. Diagnóstico endoscópico y tratamiento por laparoscopia. A propósito de un caso. Rev Acircal. 2015;2:72-83. 